\title{
Iliac vein injury after anterior transforaminal lumbar interbody fusion cage migration
}

\author{
Catarina Aleixo*, Ricardo Santos Pereira, Henrique Sousa, \\ Pedro Seabra, José Marinhas, Filipe Lima Santos
}

Department of Orthopedics, Centro Hospitalar Vila Nova de Gaia / Espinho, Vila Nova de Gaia, Portugal

Received: 02 December 2020

Accepted: 11 January 2021

\section{*Correspondence:}

Dr. Catarina Aleixo,

Email: catarinabpaleixo@gmail.com

Copyright: () the author(s), publisher and licensee Medip Academy. This is an open-access article distributed under the terms of the Creative Commons Attribution Non-Commercial License, which permits unrestricted non-commercial use, distribution, and reproduction in any medium, provided the original work is properly cited.

\begin{abstract}
Transforaminal lumbar interbody fusion (TLIF) is an effective treatment for many spine conditions. Anterior cage migration is one of the known complications and major vessels injury after that is a rare but potentially disastrous complication. We present a case of a 65-year-old female patient who underwent a TLIF for the treatment of an instable low grade spondylolisthesis. During the procedure, anterior dislodgment of the cage was verified and it was not possible to retrieve it by this approach. Has no bleeding or change in hemodynamical status was verified, it was decided not to proceed to removal at that moment. A CT-scan was performed and showed the position of the cage migrated through the posterior wall of the confluence of the left internal and external iliac veins. A new surgery was performed by an anterior approach to remove the cage and repair the vessel injury, by a vascular surgeon. In this case, cage migration occurred mostly because of implant malfunction. Surgeons must be aware that anterior cage migration can cause vascular injuries, and removal of this implants is effective by an anterior approach but a vascular surgeon must be part of the team.
\end{abstract}

Keywords: TLIF, Iliac vein injury, Cage migration, Great vessels injury, Spine surgery

\section{INTRODUCTION}

The procedure of transforaminal lumbar interbody fusion (TLIF) has become increasingly popular for the treatment of degenerative disc disease, spondylolisthesis and lumbar stenosis with instability. ${ }^{1}$ Despite being a safe and effective procedure, complications with cage migration are described.

Most perioperative cage misplacement are posterior or due to cage subsidence. ${ }^{2}$ Anterior cage dislodgement can cause serious problems and although major vessel injury after spine surgery is an infrequent complication, it is associated with a high mortality rate..$^{3-5}$

We present a case of an anterior cage dislodgement with consequent iliac vein rupture.

\section{CASE REPORT}

A 65-year-old, obese, female patient presented with longterm low back pain radiating to left leg, and resistant to conservative treatment. Complementary diagnostic tests revealed a severe discopathy and grade II isthmic spondylolisthesis. The patient was proposed for surgical treatment - L5S1 decompression and TLIF. The entire preoperative study was carried out, and the patient was sent to nutritional consultation for perioperative weight loss.

The surgical procedure started with a posterior decompression with left facetectomy and pedicle screw insertion. The left L5S1 disc was prepared via transforaminal approach and an $8 \mathrm{~mm}$ rectangular-shaped PEEK cage filled with autologous bone was inserted. 
During the introduction the cage, on impaction, it disconnected from the holder and migrated anteriorly, and it was not possible to retrieve it. No bleeding was observed and the patient remained hemodynamically stable. It was decided not to perform an anterior approach for cage retrieval at that time. The hemoglobin levels, arterial blood pressure and pulse were monitored closely during the postoperative period and were all stable.

The patient was kept in absolute bedrest and an X-ray (Figure1) and CT-scan (Figure 2) were performed. Both images studies confirmed an anterior cage migration near the great vessels. There was no hematoma visible in the vicinity of the cage. It was then decided to reoperate by an anterior approach to assess any injuries and extract the cage.

This surgery took place one week later, through an anterior retroperitoneal approach, with the help of a vascular surgeon. It was found that the cage had migrated through the posterior wall of the confluence of the left internal and external iliac veins. The cage was successfully extracted and the vein was immediately repaired with direct suture by the vascular surgeon. There was a decrease in the hemoglobin level, from 13.4 to $9.3 \mathrm{~g} / \mathrm{dL}$, but no need for blood transfusion.

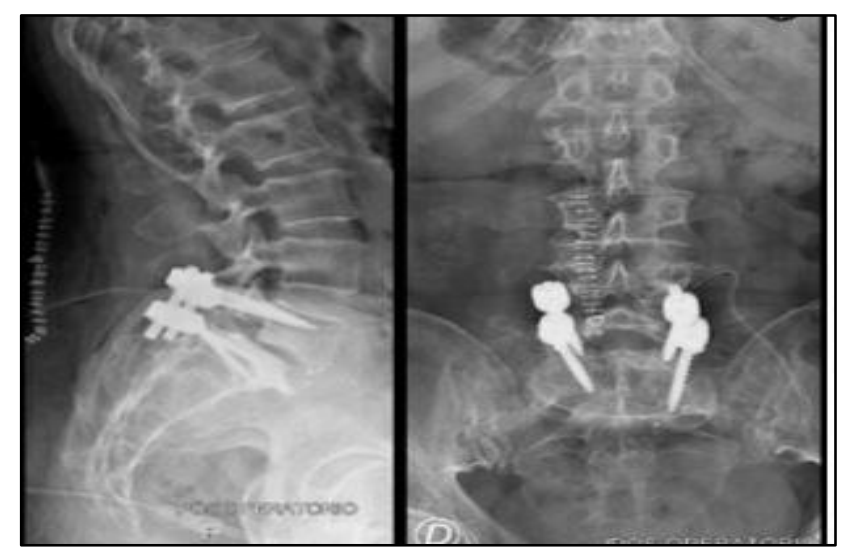

Figure 1: Post-operative X-ray with anterior cage migration.

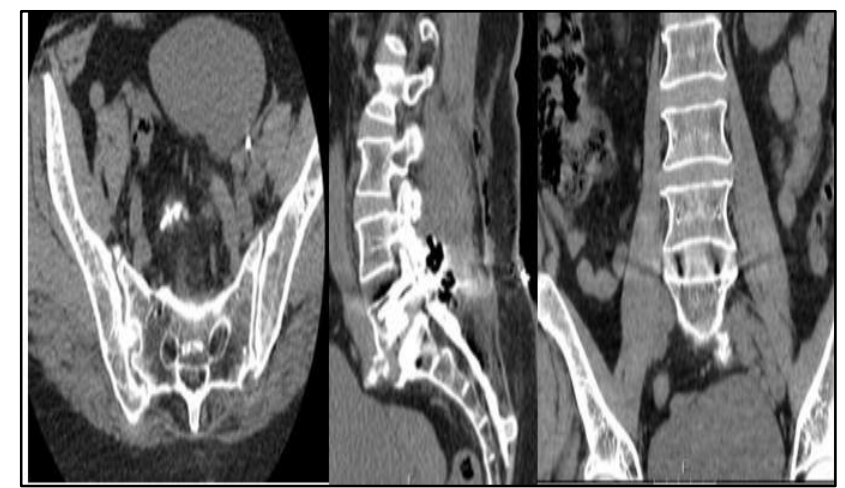

Figure 2: CT-scan with anterior cage migration.
In the immediate postoperative period, the patient was kept in absolute rest for 3 days and its hemodynamic status and hemoglobin were monitored.

One week later, the patient underwent a third surgery, with the implantation of another TLIF PEEK cage of $10 \mathrm{~mm}$ height, with no complications (Figure 3).

The patient had a good clinical evolution, maintaining only slight hypoesthesia in the left leg, with no neurological deficits, and was discharged 4 days after the last procedure.

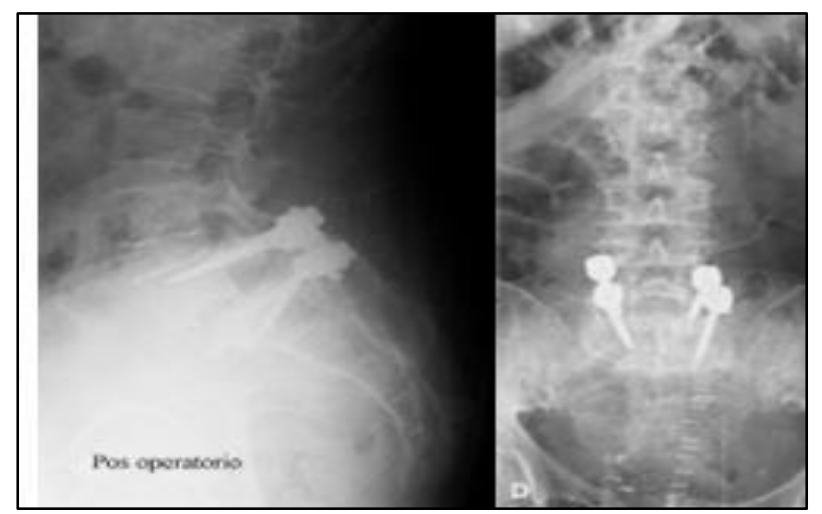

Figure 3: Post-operative X-ray.

\section{DISCUSSION}

TLIF has become a common surgical method of spine fusion and is an effective treatment for patients who have unstable low grade istmic spondylolisthesis, unresponsive to nonsurgical treatment. ${ }^{6}$

Very severe complications may be seen in spinal surgery due to the proximity of the spinal cord and vascular structures to the operative field. ${ }^{6}$ Major vessel injury after spine surgery is an infrequent but disastrous complication, with the literature suggesting less than $0.01 \%$ incidence. ${ }^{7}$

Cage migration almost always occurs in a posterior direction. ${ }^{9}$ Migration to the retroperitoneal region is a rare condition in the literature, and almost all the case reports are about posterior lumbar interbody fusion cages, with a small number of cases reporting TLIF cages dislodgement. . $2,6,8^{2}$

Some risk factors for cage migration were identified: advanced age, low bone mineral, small cages, oversized cages, rectangular-shaped cages, excessive curettage with tearing of the anterior longitudinal ligament (ALL) and strong impactation. ${ }^{1,2,6,8,9}$ Technical errors by inexperienced spine surgeons were one of the main causes found for this complication. The anterior longitudinal ligament attaches firmly to the anterior surface of the vertebrae and is not as strong on the lateral side. ${ }^{2}$ In our case, in a retrospective analysis, we found some technical errors and implant-related problems - the choice of a small 
cage, with minor radiolucent markers, strong impaction and its inadvertent disconnection from the holder.

There is no wide consensus about the ideal time for surgical exploration of the abdominal cavity whenever there is a cage migration. Ignacio et al recommended early exploration and removal of the cages and damage repair (if present), as late abdominal exploration could lead to more severe outcomes in case of antepulsion of cages. ${ }^{8,10}$ Other authors have claimed that early cage removal was not necessary unless an intraabdominal organ or vascular injury occurred..$^{8,11}$

In the presented case, during the first surgery there was no vascular surgeon on call. Given that the patient presented with no hemorrhage during the surgery and was hemodynamically stable, a decision was made not to proceed immediately to cage removal. Once a postoperative CT was obtained, and the position of the cage was confirmed, a revision surgery through an anterior approach was immediately scheduled to be performed with the help of a vascular surgeon.

\section{CONCLUSION}

In this case, anterior migration of the TLIF cage occurred mainly because of an implant malfunction. Surgery via an anterior approach is an effective way for safe removal of anteriorly migrated implants, but surgeons must be prepared to address vascular injuries and it is advisable that a vascular surgeon be part of the operating team.

Funding: No funding sources

Conflict of interest: None declared

Ethical approval: Not required

\section{REFERENCES}

1. Zhao FD, Yang W, Shan Z, Wang J, Chen HX, Hong $\mathrm{ZH}$ et al. Cage migration after transforaminal lumbar interbody fusion and factors related to it. Orthop Surg. 2012;4(4):227-32.

2. Murase S, Oshima Y, Takeshita Y, Miyoshi K, Soma $\mathrm{K}$, Kawamura $\mathrm{N}$ et al. Anterior cage dislodgement in posterior lumbar interbody fusion: a review of 12 patients. J Neurosurg Spine. 2017;27(1):48-55.

3. Ariyoshi D, Sano S, Kawamura N. Inferior vena cava injury caused by an anteriorly migrated cage resulting in ligation: case report. J Neurosurg Spine. 2016;24(3):409-12.

4. Bingol H, Cingoz F, Yilmaz AT, Yasar M, Tatar H. Vascular complications related to lumbar disc surgery. J Neurosurg. 2004;100(3 Suppl Spine):249-53.

5. Papadoulas S, Konstantinou D, Kourea HP, Kritikos $\mathrm{N}$, Haftouras N, Tsolakis JA. Vascular injury complicating lumbar disc surgery. A systematic review. Eur J Vasc Endovasc Surg. 2002;24(3):189-95.

6. Oh HS, Lee SH, Hong SW. Anterior dislodgement of a fusion cage after transforaminal lumbar interbody fusion for the treatment of isthmic spondylolisthesis. J Korean Neurosurg Soc. 2013;54(2):128-31.

7. Pawar UM, Kundnani V, Nene A. Major vessel injury with cage migration: surgical complication in a case of spondylodiscitis. Spine (Phila Pa 1976). 2010;35(14):E663-6.

8. Ceylan D, Yaldiz C, Asil K, Kaçira T, Tatarli N, Can A. Intraoperative antepulsion of a posterior lumbar interbody fusion cage: three case reports. Pan Afr Med J. 2015;20:342.

9. Jin L, Chen Z, Jiang C, Cao Y, Feng Z, Jiang X. Cage migration after unilateral instrumented transforaminal lumbar interbody fusion and associated risk factors: a modified measurement method. J Int Med Res. 2020;48(2):300060519867828.

10. Proubasta IR, Vallvé EQ, Aguilar LF, Villanueva CL, Iglesias JJ. Intraoperative antepulsion of a fusion cage in posterior lumbar interbody fusion: a case report and review of the literature. Spine (Phila Pa 1976). 2002;27(17):E399-402. d

11. Heary RF, Mummaneni PV. Editorial: Vascular injury during spinal procedures. J Neurosurg Spine. 2016;24(3):407-8.

Cite this article as: Aleixo C, Pereira RS, Sousa H, Seabra P, Marinhas J, Santos FL. Iliac vein injury after anterior transforaminal lumbar interbody fusion cage migration. Int J Res Orthop 2021;7:428-30. 